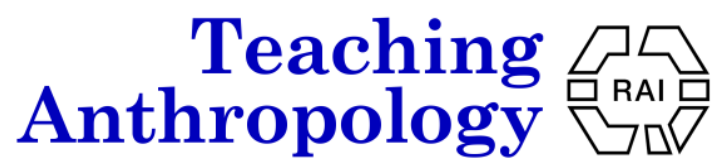

2022, Vol. 11, No. 2, pp.108-117.

Developing Teaching: Reports and Reflections

\section{Animal Farm as a Heuristic Tool for Classroom Teaching of Social Movements}

\author{
Sweta Tiwari \\ Department of Sociology, Mahatma Gandhi Central University, Bihar, India
}

\begin{abstract}
Social movements are a part of the curriculum of Anthropology and Sociology in higher education institutions in India. Traditionally, these courses are taught via snippets of some major social movements accompanied by theoretical texts by acclaimed scholars and there is little scope for individual teachers to change course content. While these texts are valuable, teaching these courses I found students struggled to make initial engagement with many of the prescribed texts and often became tense or anxious about the material. Students viewed social movements with antipathy and as a hindrance to stability, influenced by the political narratives and media representation of social movements as a disruption to solidarity. They often struggled to connect to the themes and issues of the Social Movement course, positioned within their own prisms of religion, caste, class, gender, and political sympathies. This created a gap in understanding for these students in an Indian classrooms.
\end{abstract}

In this article, I vindicate the use of Animal Farm by George Orwell as a heuristic tool, taught alongside the standard texts, to help students grasp the nature of social movements in theory as well as in praxis. Teaching and learning social movements require a certain amount of empathy and openness to untangle students from their own biases. Turning to fiction can help because students can connect and become invested in the story, after which point parallels to the academic texts or real-life social movements can be drawn. With its subtle literary techniques, Animal Farm elaborates on the social, political, and economic background for a social movement. Set in the animal world, it is a parable that is equidistant to human orientations and consequently makes an excellent starting point to distance students from their biases and preconceived ideas. This in turn helps them develop a reflexive understanding from which to engage with the core texts.

Keywords: Social Movements, Animal Farm, Heuristic tool, Teaching Anthropology, Reflexivity, Empathy.

\section{Introduction}

As I begin to reflect on the questions of teaching social movements, I ponder over the social movements taking place in educational institutes in India (Prasad, 2020; Iftikhar, 2021). It reminds me of dramatic revolutions of students' protests in Germany, 'hot autumns' in Italy and many more historical events which have shaped the world. As a teacher, and an individual observing social movement, I realise that social movements are not as neatly organised as they seem to be in retrospect. A social movement can be a state of total chaos which is influenced not only by strategic moves, but by many unprecedented events of a purely accidental nature. Social Movements can be a collective mobilization (Tilly, 1978), nestled in some form of social consciousness (Jasper, 2004). Likewise, when students come to study a course on social movements, they are also not neatly organised. They come from different backgrounds, ideologies, and experiences. The social position of students in the class affects the process of learning and can create barriers to engagement with prescribed texts and understanding social movements.

It is well known that Animal Farm was a roman-a-clef'that was set in the historical context of the Russian Revolution. The rise and fall of communism in Russia along with the major leaders of the revolution can be seen through the allegorical representations in Animal Farm. But as is the case with any good work of art, Animal Farm transcends the narrow specificity of historical incidents and becomes an overarching narrative that can speak to many more social movements. It can serve as a heuristic tool to teach social movements and endow students with a reflexive lens to study the events happening around themselves. The text draws the attention of students to the centrality of the event and the different kinds of social interactions which shape the social movement. Fictional texts, such as Animal Farm, are useful for teaching with because the text transcends the barrier of social 
stratifications. A group of animals, described in Animal Farm, are bereft of class, caste, gender, colour, religion, or any other form of social structures which creates inequality among humans. It creates a space where the dynamics of struggle are to be viewed not from where 'I stand' but from where the characters are positioned. In this way, Animal Farm provides a verstehen approach for students to learn about social movements by overcoming the barriers of their own social positions.

\section{Challenges in Teaching Social Movements}

As an Assistant Professor in the Department of Sociology and Social Anthropology at a newly established Mahatma Gandhi Central University in Bihar, India, I was assigned the task of teaching a course on social movements to the undergraduate students coming from English, Political Science and other allied disciplines of humanities and social sciences. Social movements is an area of study that is neither fully historical nor is purely theoretical. Every social movement is different from the other. They can differ in aims, sometimes in methods, arising out of very different contexts or circumstances. Studies of social movements are similarly diverse, delving into understanding the role of individual agents, the power of media, informed consciousness and measurable outcomes of the movement, emerging strategies, and the like. They have also become an important part of course curriculum in social sciences and humanities. The recent curricula of both anthropology and sociology for undergraduate students prescribed by the University Grants Commission (UGC) include courses on social movements ${ }^{2}$. UGC is a statutory organization of the Government of India, for the coordination, determination, and maintenance of standards of teaching, examination, and research in university education. The prescribed model syllabus under Choice Based Credit System (CBCS) as initiated by UGC is followed by all higher educational institutions in India. These courses are either offered as core or general elective papers.

Comparing the syllabi of courses on social movements being offered in degree programmes of anthropology and sociology across several universities in India, I found the curriculum spread across diverse themes of social movements, and frequently reduced to descriptive detail of what happened, when, where, how, and why. Most of these studies have pertained to collective actions, the need for change in society or suffocating institutional structures that led to social movements. There are many empirical works on social movements, set in different eras and geopolitical frames. The essays and articles prescribed in the syllabus are mostly theoretical in nature or are case studies of various social movements in India and abroad. Cox and Nilsen also realise this predicament and state that "canonical social movement theory operates with a deeply reductive conceptualisation of social movements" (2017, p. 118).

Traditionally these Social Movement courses are taught via dry case study fragments of some major social movements accompanied by theoretical texts. The course outline and the reading materials are pre-determined, and courses do not deviate from this. However, I found my students displayed a perceivable lack of interest in these abstract texts. Even though I was excited to teach what I knew to be a dynamic and socially relevant topic, my students seemed to be uninspired by the suggested readings. Teaching is a comprehensive activity which simultaneously requires understanding and a student's active engagement with knowledge. As a teacher, I found this lack of interest challenging because I did not have complete control over the texts, and hence I had to find alternative ways of engaging students with the course.

Here it will be pertinent to mention the demography of the students in my classroom at Mahatma Gandhi Central University (MGCU). An Act of Parliament 2009 saw the establishment of Central Universities, MGCU being one of them, in remote areas of the country to ensure fair and accessible education to all. As per a provisional data on Census of India 2011, out of the total of 1210.2 million population in India, a sizeable population of 833.1 million or $68.84 \%$ is rural (Census of India, Provisional Population Totals, 2011). The regional disparity in Gross Development Productivity (GDP) is also reflected in the demography of the students enrolling in our courses. A typical classroom, in a low economic zone, one like ours, has a rural-urban divide and a normative caste, gender and religious consciousness. A large section of students come from agriculture-based families, middle class families, followed by casual wage labour and Muslim students, not to mention a disparate gender ratio in favour of boys. These students hailing from the aforementioned social positions can wrestle with abstract concepts of social movement theories which are at a disjunction with their immediate cultural experiences.

In general, social movements in India, both in practice and theory, are disconnected from the personal history and lived experiences of these students. The most popular social movement that students recognise is the Indian 
Freedom Movement. Descriptions of the Indian Freedom Movement are part of course-curricula at school level education. The freedom struggle is significant in the making of the modern India. The national leaders of the Independence movement, the regional struggles for freedom and associated freedom fighters are not just a part of school syllabi but are also associated with national collectivism. The events of the freedom struggle and the freedom fighters have become a part of the Indian household through popular cinema, television, theatre, folk performances, and literature. The presentation of this national freedom struggle transgresses all social hierarchy and stratifications. It engages the community with a sense of collectivism and national values. Even though students were not an eyewitness to it, it is part of their lived national identity, and they emotionally connect to it. Apart from this freedom struggle movement, all other movements, like farmers movement, workers movement, environmental movements (such as Chipko Movement in India), movements for state reorganisation (Telangana Movement in India), appear distant and often reduced to thin descriptions of the event in many texts. Some social movements, like LGBT+ movements, civil rights, women' rights and anti-war movements can be unrelatable for these students who are geographically or socially distanced from these concerns. Theories of social movements are deeply entrenched in understanding the socio-cultural positions of those who struggle across the globe. Teaching and learning social movements interrogate the histories of these struggles often by questioning social realities and calling out privilege. These "uncomfortable" issues become intense at intersections of caste, class, and gender in classroom teaching. They articulate as a challenge to the existing normative structure the students belong to. Overcoming this is stifled by students who have no immediate experience of any social movement that can resonate with texts, and who often hold a reservation towards the disruptive 'activism' found in social movements.

Social movements revolve a lot around institutions, power, mobilising structures, collective identity, social network, contentious politics, and strategies. To comprehend each of the above-mentioned concepts discretely or in context of a few others is easy. But to analyse the intersections of inequality across these concepts in the praxis of social movements adds to the complexities of the learning for an 'uninitiated' batch of students. I refer to them as 'uninitiated' primarily because of their preconceived notion of social movements as a series of events that disrupts order. Their personal experience of social movements is shaped through popular media narratives, commentaries on television, and a populist government approach that presents social movements as 'bad'. Rich theoretical notes and case studies on the peculiarities of immigration, climate, gender, global justice leaves students with an unresolved tension of identifying and engaging with thematic areas that go against what they have been led to believe and takes them beyond their personal socio-cultural realm. These movements, as they are presented in core texts, fail to communicate across cultural boundaries. The prescribed course does not acknowledge enough the need for construction of a holistic understanding of the subject and disenfranchises the practice of reflective inquiry in the discipline. For example, there is a case study titled "Democratising Science Movements: A New Framework for Mobilisation and Contestation" by Sabrina McCormick (2007) prescribed in the syllabus. I find these case studies to be engaging, and they legitimise the theoretical underpinnings of social movements, yet they failed to stir the imagination of the undergraduate students. I needed to understand why and find a way to demystify social movement and enable the students to engage in the classroom. I found inspiration in Boler's words: "Within the culture of enquiry and flexibility a central focus is to recognise how emotions define how and what one chooses to see and conversely not see" (Boler, 1999, p. 177).

On the first day of my lecture on social movements, my students were critical about the protests in several university campuses demanding fee reduction, safe campus, and equal opportunities for all. The students believed university to be a place where one should quietly study, obtain a degree, and leave for a fruitful career. Involvements in social movement or protest were thought to potentially put their academic and career opportunities at risk. They looked at protests with dread, and the protesters with antipathy. Paradoxically, they had high reverence for those who had led successful protests 'in the past' that they had studied in their history books or through popular legends. For example, the Champaran Satyagraha is celebrated locally to foment the identity and history of the place and people where my university is situated. Champaran Satyagraha refers to the Indigo Movement against the teenkathia system which forced the ryots (peasant cultivators) to plant indigo in their agricultural lands. It is regarded as a crucible of Indian freedom struggle. But apart from these 'historic' cases, students felt social movements to be detrimental to social stability, so it was with some degree of trepidation that a few of my students asked me whether they would be taught how to protest.

Juggling with the abstract concepts of organisational forms, political agencies, media role and collective actions in often quite different spatio-temporal zone, students fell back on the familiarity of judging social movements as something that ruptures social harmony. While putting together the collection of readings, I therefore felt the 
need for an introductory frame to help them lose "meaning and connection with knowledge they believe they possess" (Orlandi \& Anderson, 2012, p. 25). Students needed a relatable frame of reference that could sharpen their analysis and sense of why social movements are relevant. Written in an accessible style that speaks to all, Animal Farm subtly addressed their scepticism and reservations towards social movements. Animal Farm offered a promise to capture the "dynamics of social movement organization and mobilization, taking into consideration the objective and subjective conditions that lead to formation and development of social movements" (Berberoglu, 2019, p. 4). Animal Farm offered a way for students to viscerally engage with themes of power, politics, solidarity, struggle, and justice, bringing the students closer to identifying with the themes of social movement.

\section{Animal Farm: A Heuristic Tool to Teach Social Movements}

In a situation where the syllabus is dictated, where there is little control over the choice of core texts, teaching social movements alongside George Orwell's Animal Farm served as a heuristic tool to break away from traditional lectures outlining the history of various social movements. Animal Farm creates an engaging space to form fruitful insights into the socio-political structures, institutions, actors, and agencies of social movements. It brings out the dynamic interaction between the power holders and the powerless in a stratified society. It shifts the focus from one-dimensional accounts of social struggle to a multi-layered and comprehensive study of the multiple facets of social movements. With state as the central institution, Orwell's Animal Farm is a narrative of the oppressed and subaltern of various kinds in the present world.

The Social Movements syllabus delineates the following four social movements as case studies a) Farmer's Movements; b) Dalit Movement; c) Women Movement in Telangana; and d) Science Movements; through articles by eminent social theorists (UGC). Such cases, even though relevant in the Indian context, require an amount of empathy and understanding among the students which can be hindered by their social position, gender, caste, and other demarcations. I found students often held stereotypical assumptions about social movement and considered the culture of protest incompatible with what they perceived to be the normative values of their society. Orwell's Animal Farm, set as a parable in the animal world, is equidistance to these human positions and thus is approachable as a neutral frame of reference for teaching social movements. Animal Farm not only parodies a socio-political context but allows students to reflect while reading from outside a position that prejudges, or assumes prior understanding derived from their own caste, class, or gendered experiences and media influences. In the following sections, I share the practicalities of how I used Animal Farm to teach social movements, focusing on how it complements the theoretical and practical understanding of the course, in the hope that others facing similar challenges might find it useful.

\section{Introducing the Text}

To familiarize the students with the preconditions and multitude of dimensions of any social movement, I introduced Animal Farm in my class as an activity for extended learning. At first, the students were amused by the idea of animals protesting and leading a movement, which I left unaddressed till they finished their reading. For the ease of teaching and learning, I took to theatrical narration of the text and drew parallel from real world movements. I divided the text Animal Farm into four stages of social movement like that of Blumer (1969). The division of the text facilitated the students in becoming reflexive audience to the social conditions of the animals, their discontent, and its transformation into a movement. The delineated stages addressed the concerns and biases that the students had about an ideal condition to revolt, resist and stage a disorder. I allowed my students to situate the actors, the leaders, the operative logic, and the abstract concepts of social movements in the text, as it progressed. The animal world does not align with the cultural image of normative social order. This enabled the students to look at the pre-conditions, causes, and nature of the social movement from a neutral perspective beyond their pre-conceived schema of social order and hierarchy. As a result, they looked at the characters with an objective lens of enquiry. Under the influence of evocative vocabulary and an objective understanding of misery and oppression, they become active participants in the making of 'the movement'. I divided Animal Farm into the followings four stages: Preconditions; Comrades/collectivism; Bureaucratizing; and End/alternate beginning.

\section{Stage I: The Pre-condition for Social Movement:(Animal Farm: Chapter I-II)}


To teach social movement, I needed to make my students understand the cause of collective discontent against the established order. How does it all begin? In the first part students identify Old Major as a traditional authority. The text establishes the nature of life the animals have in the farm. The vivid detail of prevailing situation on the farm captures the social conditions of the animals and evokes a sense of misery of the animals. At this juncture students realise that the common thread that unites different animals is discontent towards their living condition. An articulate speech by Old Major acts as an initiation to mass participation towards a common goal. Blumer (1969) refers to this stage as 'social ferment'. Social movements are perceived as 'organized' or 'collective effort' towards changing the institutions, values, attitudes, in society. Any social movement does not just happen. The pre-condition for any movement to take stage is collectivism. The power structures become seemingly oppressive and there is a felt need to challenge the existing system. The need for change, the translation of individual's discontent into collective, and merging of the plural identities is dramatically represented in the first two chapters of this parable.

\section{Stage II: Comrades/Collectivism}

The meeting proceeds towards the stage of "What then must we do?" It resonates with the second part when the Movement becomes organized. Prominent leaders may begin to emerge. The social world gets divided into the oppressor and the oppressed. The section maps the making of an organization. A brief discussion on who must be addressed as 'Comrade' brings to light that a common address, associates them together by withholding their individual identity and bringing them all to the receiving end of the oppressive system. "Man is the only real enemy we have. Remove Man from the scene and the root cause of hunger and overwork is abolished forever." (Orwell, 2019, p. 4). The speech of Old Major raises the consciousness of the animals around the "tyranny of human beings" (p.5). Sceptical voices emerge such as "If the rebellion is to happen anyway, what difference it makes whether we work for it or not?", "Mr. Jones feed us", "He is the Master" (p.11). The students face the mirror-image of their own reluctance towards participating in a movement. This can exemplify Rex D. Hopper's (1950) statement that states that the "unrest is no longer covert, endemic, and esoteric; it becomes overt, epidemic, and exoteric. Discontent is no longer uncoordinated and individual; it tends to become focalized and collective". He goes on further, "this is the stage when individuals participating in the mass behaviour of the preceding stage become aware of each other" (p. 273).

\section{Stage III: Bureaucratizing the Revolution}

Two young boars take up the responsibility of bureaucratizing the revolution. The idea of revolution is materialized, and the Old Major's teachings are developed into a system of thought, Animalism. Eyerman and Jamison (1991) posit that "by articulating consciousness, social movement provides public spaces for generating new thoughts activating new actors, generating new ideas" (p. 161-166). The text in its initial chapters shows the rise of new leadership after the demise of Old Major. This stage is marked by strategies and organisational planning which Blumer (1969) refers to as "formalization," (De la Porta \& Diani, 2006). The ideology of Animalism elucidates the strategies and resources that come into play for the success of their movement. Snowball and Napoleon, the pigs not only provide the knowledge base derived from the preaching of Old Major, but they also provide fool proof protest tactics which ensures victory for them first in the creation of the Animal Farm and later in chasing out the invading men in "Battle of the Cowshed". There are several other animals viz Boxer, the horse (representing strength), Benjamin, the donkey (representing wisdom) and Squealer, the pig (minister of propaganda) among others who play an important role in the movement and in the subsequent order established after the eviction of Mr Jones. Here the students can situate the binaries of Old Social Movements' class struggle and the New Social Movements' appeal to social justice and individual freedom in the animal rebellion.

\section{Stage IV: The end/alternate beginning}

Initially the animal mobilisation is aimed at overthrowing the centralised and oppressive structures of the farm. The rest of the chapters highlight the post protest situation. The celebration is followed by destroying everything that reminded them of Mr. Jones. The throwing of the nose rings, dog chains and cruel knives add to the dramaturgy of social movements (Melucci, 1995). It engages the students in reinterpreting the roles of the animals as the change begins. What happens after the movement ends? Do all movements materialise into success? There are several ways in which a movement may end. The end is not necessarily marked by just success or failure (Miller, 1999). The Manor Farm is renamed as Animal Farm. Apart from the cursory change of name 
there is a need for reconstruction of a new order. Rajender Singh (2001) describes the need of 'order' as "cleverly manipulated in defence of the power and privileges of new political class and 'new leader" (p.121). What happens in Animal Farm now is of special interest. Napoleon emerges as hegemonic leader of the animals, backed by the sycophant Squealer while Snowball gets ousted from the corridors of power. The homogenous group of the animals breaks into a hierarchical order which replicates the previous system. Gradually the animals end up in an establishment of the same oppressive structure that they sought to overthrow in the first place. They think that they are in an ideal setup promised in socialism. Pigs were supposed to work for the welfare of their fellow animals but became prey to the lurid temptations of power. It shows that power corrupts, and absolute power corrupts absolutely. The pigs in Animal Farm ascended to the top of the ladder of the new hierarchy through knowledge. The pigs take a privileged position and stage new rules and demand authoritarian silence from the others. It also proves the Foucauldian thesis that power creates knowledge for its own perpetuation. Initially these rules are the seven commandments devised by the pigs and approved by all the animals.

1. Whatever goes upon two legs is an enemy.

2. Whatever goes upon four legs, or has wings, is a friend.

3. No animal shall wear clothes.

4. No animal shall sleep in a bed.

5. No animal shall drink alcohol.

6. No animal shall kill any other animal.

7. All animals are equal". (Orwell, 2019, p. 16)

The animals make these rules regarding the operation of the collective so that they are all bound to be together. This new alternative institution seems better than the previous oppressive institution. Ironically these rules get amended with the passage of time and the situation worsens till it replicates the old times as is evident in the final section of Animal Farm:

As for the others, their life, so far as they knew, was as it had always been. They were generally hungry, they slept on straw, they drank from the pool, they laboured in the fields; in winter they were troubled by the cold, and in summer by the flies. Sometimes the older ones among them racked their dim memories and tried to determine whether in the early days of the Rebellion, when Jones's expulsion was still recent, things had been better or worse than now. (Orwell, 2019, p. 87)

When used with the stages described, Animal Farm can serve as a toolkit to explain the complex theories concerning human behaviour, organisation of social movements, and establishment of hierarchies among human beings. The text can also serve as a parable to understand the process of actual social movements occurring on a day-to-day basis in our surroundings. Behind the silhouettes of animals in Animal Farm, Orwell displays human behaviour, both individual and collective, when the institutions serve their needs and when they become repressive. Through Orwell's tale, students could be taught Hobbe's (1968) proposition concerning the motives of individuals coming together as collective. According to Hobbes, the human needs are built around desires and appetite. People under any circumstance would seek pleasure. In their attempts to gratify their desires and quench their appetite, in case they meet any hurdles, they will develop a kind of herd mentality and seek the company of many like-minded people to protest the status quo. When they understand that fighting alone would not help, they decide to fight together. Therefore, during protests, individuals give up their rights and power to create a collective wealth which can be a strategy or a plan or a knowledge base. Their individuality gets subsumed in the collective. They assume this collective to be an institutionalised power structure. That coming together accumulates power which prima facie appears decentralised (Jasper,2004; Meyer, 2015). They envision a mirage that a decentralised and non-hierarchical structure will be achieved through their collective struggle. Orwell's Animal Farm is a conscious narrative which validates the multi-layered nature of social movement. It evokes a range of positions from where social movement can be studied. The students engage in the transformation of discontent to protest. Manor Farm was an oppressive institution for all the animals. The animals are metaphorical representations of various social roles prevalent in any society. Animals knew that in their singularity was their failure. Even though they had the sense of rebellion, they required the collective endeavour to take up arms against Jones and defeat him. The pigs, because of their control of knowledge, use it as a tool to tap on the potential of other animals and motivate them to constitute a group with common objective. The objective was to overthrow the constraining regime of $\mathrm{Mr}$ Jones. The institutional structures of Animal Farm were deeply stratified and rooted in accumulated power. The discursive nature of the system was ousted by a collective rebellion against the farm owner and other humans. For a while, freedom from the preexisting setup was exhilarating and power seemed decentralised. But soon the anticipation of a just and fair 
establishment was ruptured, and the pigs ascended the top rung of a new hierarchical setup. This is evident when Napoleon, a participant of the movement subsequently becomes the authoritarian head of the farm and even commissions a poem written in his praise.

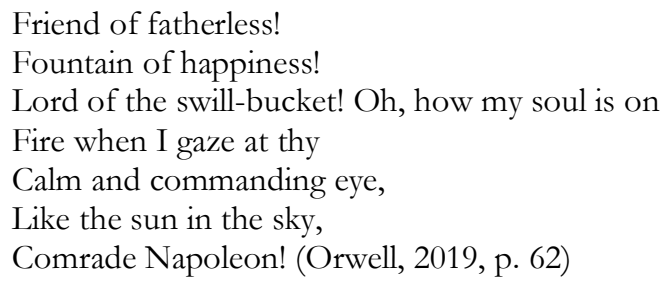

Hobbes provides dramatic colour to human actions. We find a beautiful example of that in Animal Farm. The animals on one hand, are working against an order while on the other, they are attempting to create an order of their own accord.

Louis Dumont (1966) in his book titled Homo Hierarchicus propounded a theory that human beings are hierarchical beings. In any society, by the means of various structures they create hierarchy of a definite order which might be coming from religion, purity, knowledge, skills, power, and the like. "From castles and palaces and churches to prisons and workhouses and schools; from weapons of war to a controlled press, any ruling class, in variable ways though always materially, produces a social and political order." (William,1977, p. 93). Events in Animal Farm provide a practical example to elucidate the human proclivity towards formation of hierarchies. During the course, I provided examples from Animal Farm to theoretically elucidate the life of various stakeholders, and the social structures that provide a ground for revolt and change in any social movement.

One example I drew upon was an 'anti-corruption movement' that erupted in the capital of the largest democracy of the world. In 2012, members of civil society gathered in Delhi, India, to protest the incumbent government. The people that led the movement had no previous political background of significance. Among them was a retired Army veteran, a Yoga Guru of international repute, an IRS officer and Ramon Magsaysay Awardee social worker, A Hindi poet, and an actor in Bhojpuri and Hindi cinema, a retired IPS Officer, among others. These people sought the creation of a corruption free system and demanded the passing of the Lokpal Bill as an immediate means to end corruption (Sengupta, 2014). Even though they were established in their respective fields, their collectivism was their strength. The movement they initiated gathered nationwide momentum and garnered huge support among the common masses. When the movement reached its crescendo, the members collectively came up with an alternative system which they thought would be better than the previously defunct system. They actualised their idea through the formation of a political party named Aam Aadmi Party. It is noteworthy here that the very name of the party establishes its identity as the party of the common masses, not of the elite and the rich people in charge of governance which bears a striking resemblance to the naming of "The Manor Farm" as "Animal Farm". Like Orwell's tale, there were numerous factions among the members of the movement. It so happened that two of the leading voices of the party were evicted for difference of opinions as was the case with Snowball. The retired IRS officer and the retired IPS officer were pitted against each other for the Chief Ministerial post in Delhi from two different political parties. At the same time, another member of the movement became the Party Chief of Delhi region through a national political party. The spiritual Guru dissociated himself completely from the workings of the incumbent party and so did the retired Army veteran. The poet turned politician also voiced dissent within the party and continues to do so (“Anti-Corruption Movement", The Indian Express 2019).

The participants of the afore-mentioned movement held a utopian dream of a corruption free government and are perhaps steadfast still in the pursuit of their common goal. But the revolution once complete, their paths diverged almost completely. The social movement which metamorphosed into a political party still has a lot to offer and can be fully evaluated after a certain period. But studying the intricacies of the movement through the parable of Animal Farm provides a gratifying experience to capture the polymorphous nature of social movements. Blumer (1969, p. 99) rightly mentions, "As social movement develops, it takes on the character of a society. It acquires organisations and forms a body of customs and traditions, established leadership an enduring division of labour, social rules and social values-in short a culture, a social organisation, and new scheme of life". The formation of leadership and a new social organisation through a kind of government of the common masses (epitomised by the name Aam Aadmi Party) was the ultimate stage of the movement that demanded change. Like 
Animal Farm, a revolution led to the creation of a new set of rules as the party manifesto which would also be amended from time to time. Society remains forever in a state of flux which creates order and then dissolves it. A new order has been established through a political party which went on to form a government with a historic mandate. In case this system too, over a period, creates a rigid structure like that of Napoleon, it too would provide opportunities for another struggle.

\section{Conclusion}

Social Movements are taught in most of the educational varsities in India. In academia, social movements are framed through anthropological and sociological concepts: social theories of power, structure, agency, politics, organization, exclusion, and the like. Yet, teaching a social movement course in India can be challenging as it questions the orthodoxies inherited by the cultural bearings of the students. Popular media sources and other hegemonic social structures within the Indian socio-political context often depict social movements in stark opposition to social solidarity and stability. The negative media portrayal and the hegemonic political climate fill students with an image of social movements as disruption to order, leading some to develop distrust towards movements. For me, the purpose of teaching social movements is not merely to provide students with a series of historical incidents as part of a prescribed syllabus, but to open an interaction where students empathetically engage with and understand the purpose of social movements, the experiences of struggle and oppression, and the theories that explain them. In teaching a course on social movements, it is important to highlight the situations in which movements emerge and how they trigger a need for action. To do this successfully, students should be encouraged to question the validity of their assumptions - those ideas and beliefs established under the influence of the current political climate and personal experiences.

In my teaching, I have found the ambiguity students attach to academic texts and prescribed course content emerges primarily because students are not able to relate to abstract concepts and unfamiliar experiences. To address this, it was necessary to sensitively overcome the emotional and cultural biases students had to facilitate a creative and meaningful learning space. Students coming from diverse caste, gender, religion, and economic backgrounds can have drastically different experiences that make it difficult to establish empathy and deeper understandings of a particular movement. By introducing animal characters, Animal Farm encourages students to overcome their biases, engage and empathise with fictional characters. This serves as a bridge to deepen student understanding and introduce parallels with real life examples of social movements. When read alongside the texts found in the course curriculum, Animal Farm can elucidate accounts of the socio-political and structural factors which lead to protest or call for change. The accessible text can be used to introduce the theoretical vocabulary of social movements, bridging the spatial and temporal gap which can sometimes be incomprehensible to students from a different time and space. Using parallel examples illustrated in the fictional Animal Farm, students can identify change and continuity within real events and deepen their understanding of theoretical explanations for social movements.

It is necessary for teachers like us, to challenge the ossified paradigms of teaching in Indian classrooms so that every student is given an opportunity to look beyond the barriers of learning and capture the essence of the discourse with reflexivity and objectivity. When read alongside the theoretical and historical texts in the course curriculum, Orwell's Animal Farm can render a reflexive understanding of social movements by presenting an accessible and evocative account. It can be used by teachers as a unifying 'whole' to a social movements course, a lattice work of social relations through which power, oppression, and need for social change can be made the object of enquiry. This utilisation of fictional texts could be relevant to many courses around the world where likewise, the student cohort is dramatically different to the movements studied and may have preconceived ideas about them. In particular, courses pertaining to gender, ethnicity, refugees, migration, and climate action, to name a few, which are entrenched in conflicting paradigm and theories that challenge student beliefs. Animal Farm supported the teaching of social movements by acknowledging and allowing students to look beyond their social status and preconceived understanding in order to connect to and feel solidarity with social struggles.

\section{Notes}

${ }^{1} \mathrm{~A}$ novel in which real people or events appear with invented names. 
Teaching Anthropology 2022, Vol. 11, No. 2, pp.108-117.

\section{References}

Express News Service. (2019, January 5). Anti-corruption movement ending with a political party was wrong: Former Punjab MLA H S Phoolka. The Indian Express.https://indianexpress.com/article/india/anticorruption-movement-ending-with-a-political-party-was-wrong-former-punjab-mla-h-s-phoolka/

Berberoglu B. (2019) Introduction: Dynamics of Social Movements, Revolution, and Social Transformation. In: Berberoglu, B. (eds). The Palgrave Handbook of Social Movements, Revolution, and Social Transformation. Palgrave Macmillan, Cham. https://doi.org/10.1007/978-3-319-92354-3_1

Boler, M.(1999). Feeling Power: Emotions and Education. New York: Routledge.

Blumer, H. (1969). Collective behavior. In Lee, A.M. (Ed.), Principles of sociology (3rd Ed.). New York: Barnes and Noble Books.

Chandramouli, C. (2011). Census of India 2011 Provisional Population Totals Paper-2, Volume 1 of 2011 Rural-Urban Distribution Series 1. Government of India, Census of India. New Delhi: Office of the Registrar General and Census Commissioner, India. https://censusindia.gov.in/2011-provresults/paper2/data files/india/paper2 1.pdf

Cox, L. (1999). Building Counter Culture: The Radical Praxis of Social Movements Milieux (Ph.D Thesis). Trinity College.

Cox, L. and A. Nilsen (2017). Reading neoliberalism as a social movement from above, Theomai, 35, 118-128.

Crossley, N. (2009). Making Sense of Social Movements. Jaipur: Rawat Publication.

De la Porta, D. \& Diani, M. (2006). Social movements: An Introduction. Malden, MA: Blackwell Pub.

Dumont, L. (1980). Homo Hierarchicus: The Caste System and Its Implications. University of Chicago Press.

Eyerman, R. and Jamison, A. (1991). Social Movements: A Cognitive Approach. London, Polity Press.

Foucault, M. (1980). Power/Knowledge. Selected Interviews and Other Writings. 1972-1977. New York: Pantheon.

Hobbes, T. (1968). Leviathan. Baltimore: Penguin Books.

Hopper, R. D. (1950). The revolutionary process: A frame of reference for the study of revolutionary movements. Social Forces, 28(3), 270-280.

Iftikhar, F. (2021, March 25). Indian Universities, 2010-2020: A decade in protest. Hindustan Times. https://www.hindustantimes.com/india-news/indian-universities-2010-2020-a-decade-in-protest$\underline{101616585103634 . h t m l}$

Jasper, J. M. (2004). A Strategic Approach to Collective Action: Looking for Agency in Social Movement Choices. Mobilization, 9, 1-16.

McCormick, S. (2007). Democratising Science Movements: A New Framework for Mobilisation and Contestation". Social Studies of Science, 37(4), 609-623.

Melucci, A. (1995). The process of collective identity. In Johnston, H. \& Klandermans, B. (Eds.), Social movements and culture (pp. 41-63). Minneapolis, Minnesota: University of Minnesota Press

Meyer, D. S. (2015). The politics of Protest: Social movements in America. Oxford University Press.

Orlandi, K. J. \&Anderson, B. (2012). Researching the Role of Dialogue, Writing and Critical Reflections in Unlearning for Students with Professional Backgrounds. Teaching Anthropology, 2(1), 22-27.

Orwell, G. (2019). Animal Farm (2nd ed.). New Delhi: General Press. 
Prasad, S. K. (2020, January 10). India is cracking down on university protests. Here's what you need to know. The Washington Post. https://www.washingtonpost.com/politics/2020/01/10/india-is-cracking-down-university-protestsheres-what-you-need-know/

Schussman, A., \& Soule, S. A. (2005). Process and protest: Accounting for individual protest participation. Social Forces, 84(2), 1083-1108.

Singh, R. (2001). Social Movements, Old and New: A Post-Modernist Critique. Sage Publications. New Delhi.

Sengupta, M. (2014). Anna Hazare's Anti-Corruption Movement and the Limits of Mass Mobilization in India. Social Movement Studies, 13(3), 406-413. https://doi.org/10.1080/14742837.2013.860025

Tilly, C. (1978). From mobilization to revolution. Reading, Mass: Addison-Wesley Pub. Co.

Tilly, C. (2004). Social Movements. 1768-2004. Routledge. https://doi.org/10.4324/9781315632063

University Grants Commission. "Syllabus of BA (Hons) Sociology".www.ugc.ac.in/pdfnews/6144453 BAHonors Sociology.pdf. Accessed 20 Feb. 2021

William, R. (1977). Marxism and Literature. Oxford University Press.

\section{Acknowledgements}

This paper would not have been possible without the constant support and motivation that I received from my mentors, colleagues, and friends. I am forever indebted to Late Professor Vinay Kumar Srivastava (former Director, Anthropological Survey of India) for guiding me during my Masters and Ph.D at University of Delhi. I owe my understanding towards Anthropology and teaching methodology to Professor Srivastava. Dr. R.P. Mitra and all my teachers ignited my imagination to look beyond the text into the real world and work for teaching and learning. I extend my thanks to my colleagues and friends Mahwash Bukhari, Dr.Alka Lalhall, and Dr. Umesh Patra for their exceptional support and unfailing patience throughout the gestation of this article. I am also grateful to the reviewers and editors of Teaching Anthropology journal for their insightful comments and support.

\section{Disclosure statement}

No potential conflict of interest to report. 